\title{
Editorial
}

\section{Phillip Harris}

Phillip Harris has achieved so much in his medical life that it is extremely difficult to pick out peaks of his prowess amongst a veritable alpine range of accomplishments. However, one of the pinnacles of his work must be the enormous contribution he has made to this journal. Phillip was appointed assistant editor to the journal ('Paraplegia') at the time of its inception in 1963 and has continued to serve the journal ever since that time: an amazing record of 34 years. For the last 17 years he has been editor of the journal and during this time he introduced a number of innovative features. Phillip was responsible for increasing the number of issues from four per year to twelve per year. Under his direction we have seen an increase in the number of papers being received for consideration for publication, and an increase in the scientific merit of manuscripts submitted to the journal. Examples of this include the diverse and important fields of the neuropathic urinary bladder, regeneration in the central nervous system, the question of the central pattern generator and many, many more subjects of great clinical importance as well as academic interest.

In 1995 Phillip was instrumental in changing the format of the journal with an attractive 'face lift' and changing the size of the journal to A4 which was more in keeping with clinical and scientific journals worldwide. In 1995 the name of the journal was changed to 'Spinal Cord' and the first issue under the new name was in April 1996. Before the change occurred there was considerable discussion and it was felt that the previous title was too restrictive and did not reflect the much more broad based and wide appeal of the journal which was now encompassing all aspects of the spinal cord and the spine including basic science and clinical aspects, both traumatic and non-traumatic.

Phillip Harris was Consultant Neurosurgeon at the Royal Infirmary of Edinburgh and the Western General Hospital in Edinburgh, and Senior Lecturer in the Department of Clinical Neurosciences for a total of 39 years - an amazing achievement in itself. He has been guest lecturer and visiting professor in many places in the world, including the United States,
Canada, Israel, Burma, Hong Kong, Thailand, Iran, Argentina, Uruguay, Bolivia, Peru, Sri Lanka, Norway, Japan, Cyprus . . . He served, in a senior capacity, in the World Federation of Neurological Societies, was honorary medical adviser for the planning, building and staffing of new spinal units throughout the world, including Scotland, India, Egypt, Greece, Cyprus, USA and Saudi Arabia. No wonder he is such a popular and revered figure in his speciality

$\mathrm{He}$ is the author of 85 scientific papers and 12 books and chapters in books. He was a member of examination boards in Edinburgh and Glasgow and an active member of many medical committees. He took an active part in medical education and, for example, served as chairman of the committee of management of the triple qualification of the Royal College of Surgeons of Edinburgh; the Royal College of Physicians of Edinburgh and the Royal College of Physicians and Surgeons of Glasgow, as well as being a member of the General Medical Council Committee concerned with undergraduate and postgraduate medical education.

At the annual scientific meetings of IMSOP Phillip was like a beacon, with delegates from all over the world flocking to him for advice or thrusting manuscripts into his hands. A very popular colleague and a hard act to follow!

It is with great regret that I view Phillip's departure from the editorial chair, but I extend the warmest best wishes to Phillip and Sheelagh for the future.

Phillip always said that his main medical mentors in medical neurology included Sir Charles Symonds and Dr McDonald Critchley. There is some continuity then, in that part of my medical teaching was from Sir Charles Symonds and I was Dr McDonald Critchley's last House Physician at Queen Square before his retirement! I hope that I can achieve just a fraction of Phillip's success with this journal.

LS Illis Editor 